\title{
Evaluation of Radiation Doses for Hypothetical Accident Scenarios of Egyptian Second Research Reactor
}

\author{
Nema Mohamed Kandil, Faten Salah Tawfik \\ Nuclear \& Radiological Regulatory Authority (NRRA), Cairo, Egypt \\ Email address: \\ nemakid@hotmail.com (N. M. Kandil)

\section{To cite this article:} \\ Nema Mohamed Kandil, Faten Salah Tawfik. Evaluation of Radiation Doses for Hypothetical Accident Scenarios of Egyptian Second \\ Research Reactor. International Journal of Environmental Protection and Policy. Vol. 9, No. 3, 2021, pp. 59-68. \\ doi: $10.11648 /$ j.ijepp.20210903.12
}

Received: June 11, 2021; Accepted: June 26, 2021; Published: July 2, 2021

\begin{abstract}
Inshas site is very important site, it is considered as a first nuclear site in Egypt. It contains the first and the second research reactors and other important facilities such as the Egyptian Fuel Manufacturing Pilot Plant (FMPP) which submits the fuel to the second research reactors. The goals of this paper are to assess different emergency plan scenarios, determine the effects of metrological conditions on the dispersion of the radioactive plume, and calculate the overall effective dose equivalent values (TEDE). The meteorological parameters for one complete year 2020 (hourly) meteorological data were analysed in details such as wind direction, wind speed and temperature. The HotSpot code was used to model atmospheric dispersion and its application resulted in a radiation dose profile around the site using meteorological parameters specific to the area under study. This study used more than one scenario to investigate the role of various meteorological parameters. The radionuclide source term of Cs-137 was assumed to be $2.10 \mathrm{E}+15 \mathrm{~Bq}$. The results show that the maximum dose form all postulated scenarios is about $1.1 \mathrm{E}+4 \mathrm{~Sv}$ is observed at $10 \mathrm{~m}$ from the release source for weather stability class F, which is greater than the IAEA occupational exposure limit of $0.02 \mathrm{~Sv}$ per year. The results can also show that the time of accident is a major effect on the impact of accident and then on the consequences of emergency plan.
\end{abstract}

Keywords: Accidental Release, Radionuclides, Radioactive Contaminant, Gaussian Model, HOTSPOT

\section{Introduction}

All meteorological towers related to Egyptian Meteorological Authority (EMA) have 10m height. There are only two meteorological towers in Egypt which measure the meteorological parameters at different heights. The first at El Dabaa site (the site of the first nuclear power plant) with the height $100 \mathrm{~m}$ and belong to Nuclear Power Plant Authority (NPPA) and the second at Inshas site with the height $60 \mathrm{~m}$ (Figure 1) and belong to the Egyptian Nuclear \& Radiological Regulatory Authority (ENRRA). Also, it will help in:

1) Putting an efficient emergency plan for Inshas site.

2) At up normal release for any reason at Inshas site using this data to define the evacuation area and sheltering area around the site.

Meteorological parameters such as relative humidity, wind speed, and direction and air temperature are recorded at $10 \mathrm{~m}$, $40 \mathrm{~m}$, and $60 \mathrm{~m}$ levels for the inshas tower. As part of our routine work, we received data from the tower via the internet and downloaded it to a workstation in the ENRRA department. It is critical to investigate the environmental impact of radioactive pollutants emitted by nuclear reactors during normal and abnormal operation. This is accomplished by calculating the radiation doses for the people who live near these facilities. Recently, several studies for the evaluation of dose for a hypothetical accident in a research reactor have been shown [1-4]. 


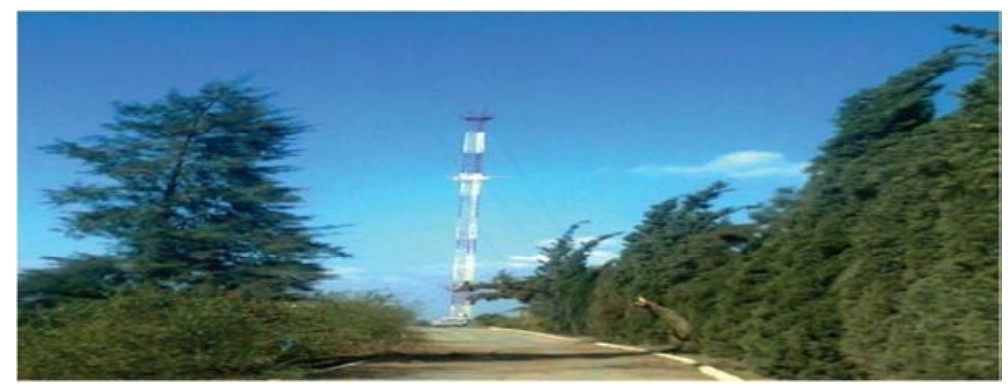

Figure 1. Inshas Meteorological Tower

\section{Materials and Methods}

\subsection{Study Area}

The Egyptian Second Research Reactor (ESRR) has a thermal power of $22 \mathrm{MW}$ [5]. It located about $26 \mathrm{~km}$ northeast of Cairo in Inshas area of Greater Cairo with Coordinates: $30^{\circ} 17^{\prime} 35.0^{\prime \prime} \mathrm{N} 31^{\circ} 24^{\prime} 32.5^{\prime \prime}$. The site occupies an area of about $10 \mathrm{~km}^{2}$, surrounded by an authority fence. The area is bounded on the west and northwest by Ismailia Canal, on the northeast and east by native farms and on the south by military factories. It is accessible through highways, such as Cairo-Belbies desert road and Cairo- Ismailia agricultural road.

\subsection{Metrological Data}

In this study we analysis the meteorological data to prepare the input meteorological file of the code which used to assess in case of hypothetical accident. The prevalent wind direction and heavily polluted area were determined by plotting the seasonal wind rose.

The seasonal and annual wind rose Figures 2 and 3 was plotted using the recording hourly wind speed and wind direction for year 2020. It is clear that from these figures that the prevailing wind are the North west, North and North east which blow to South east, South and South west. This means that in the case of leakage of pollutants, these sectors will be more polluted.

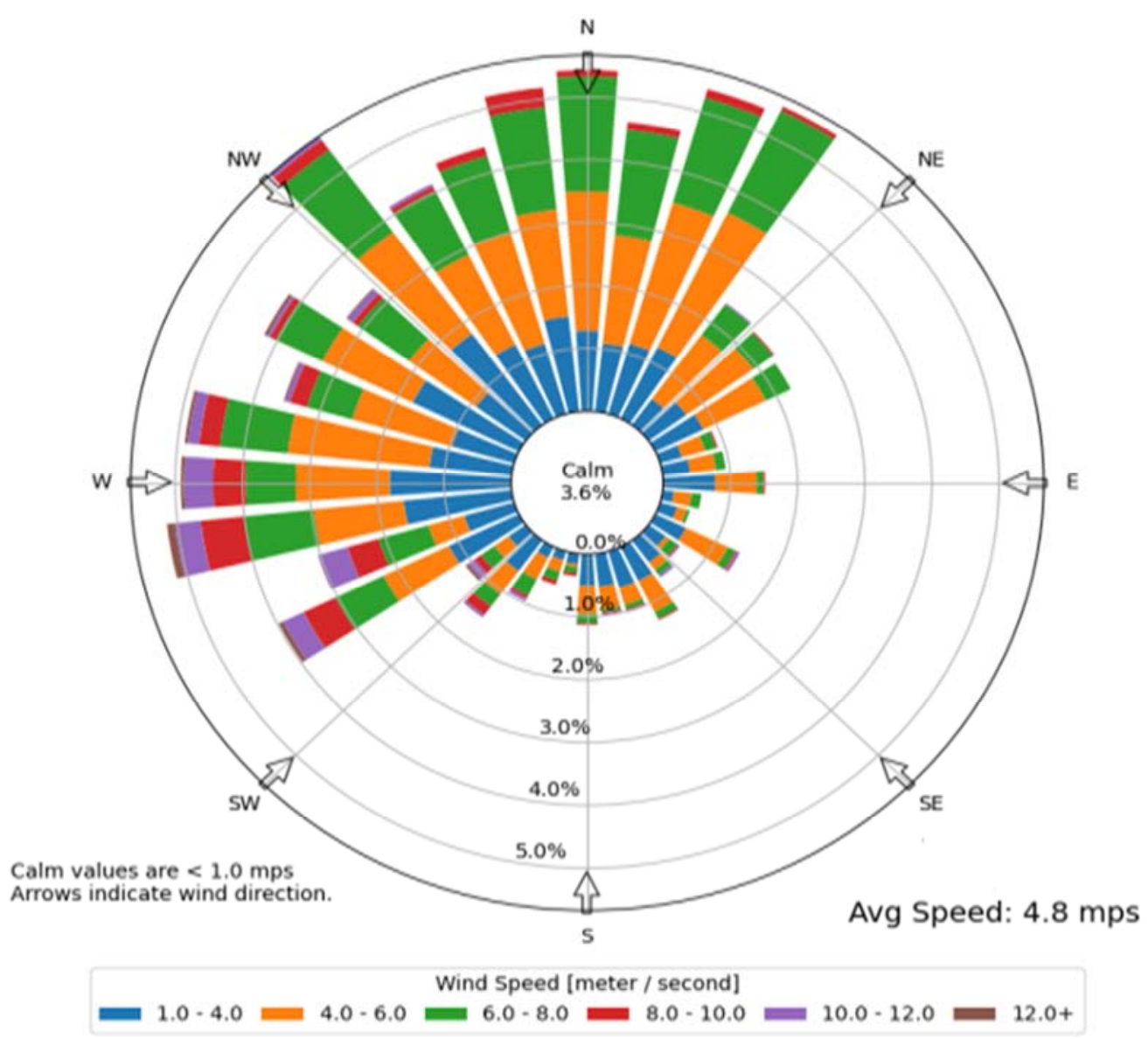

Figure 2. The 2020 wind rose for inshas. 


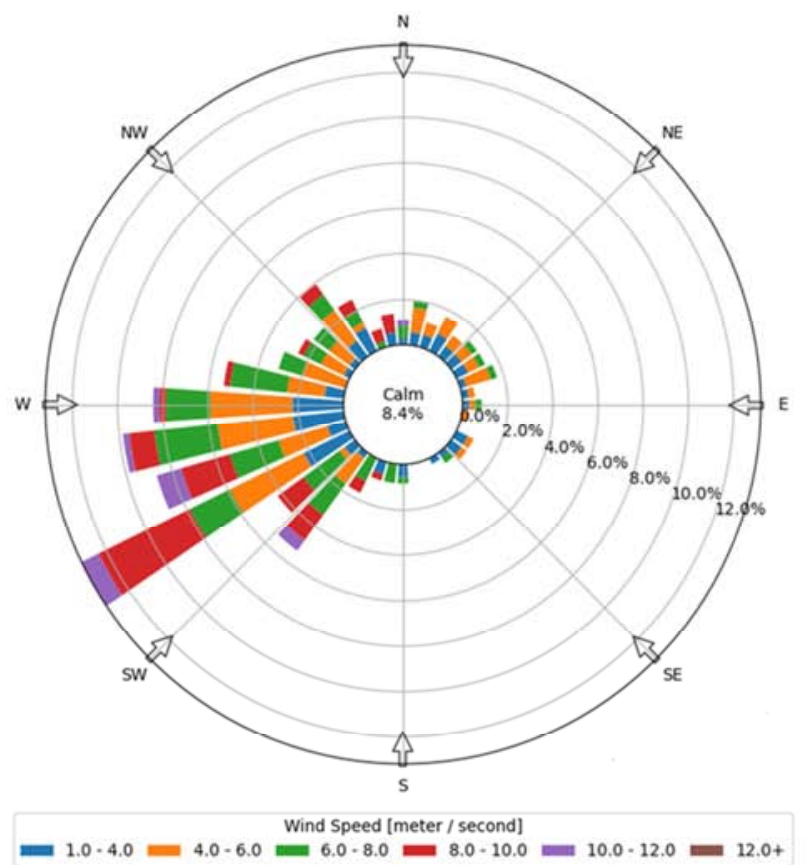

Winter

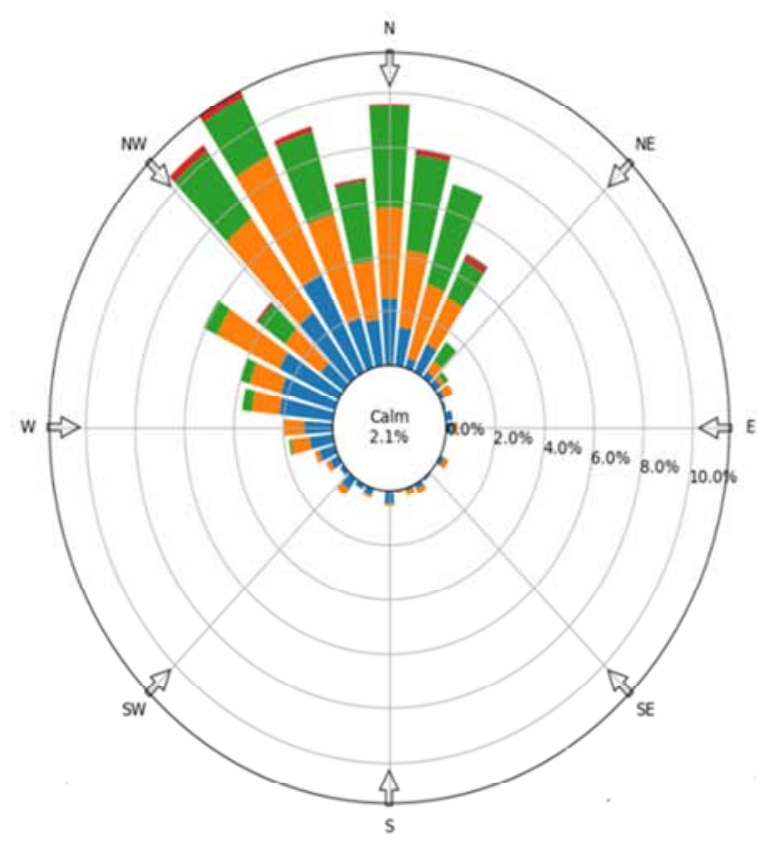

Wind Speed [meter / second]

$=1.0 \cdot 4.0=4.0 \cdot 6.0=6.0 \cdot 8.0=8.0 \cdot 10.0=10.0 \cdot 12.0=12.0+$

Summer

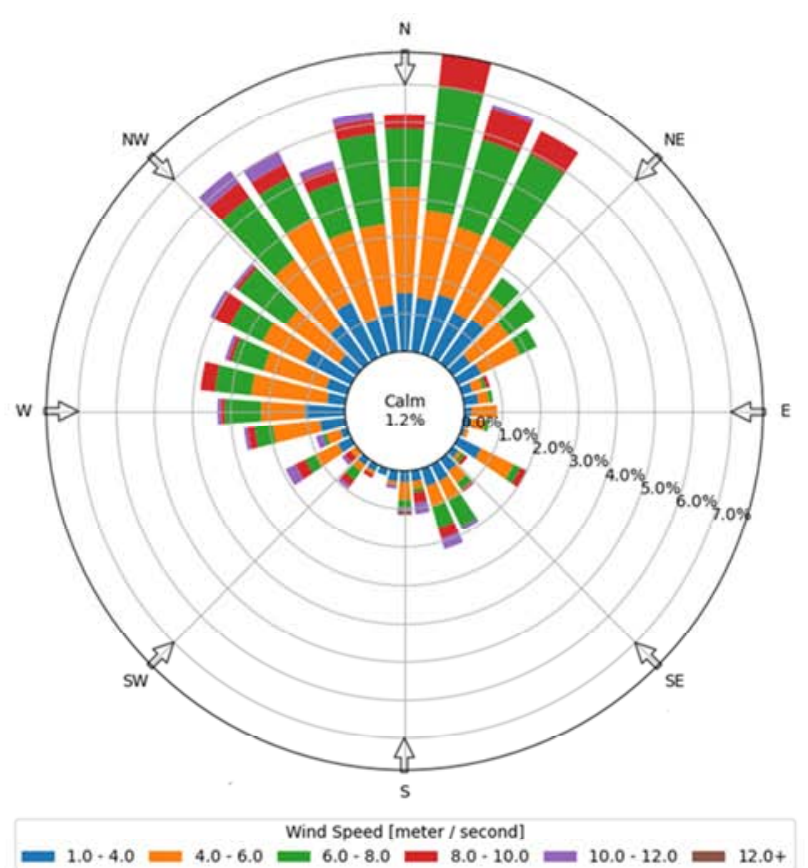

Spring

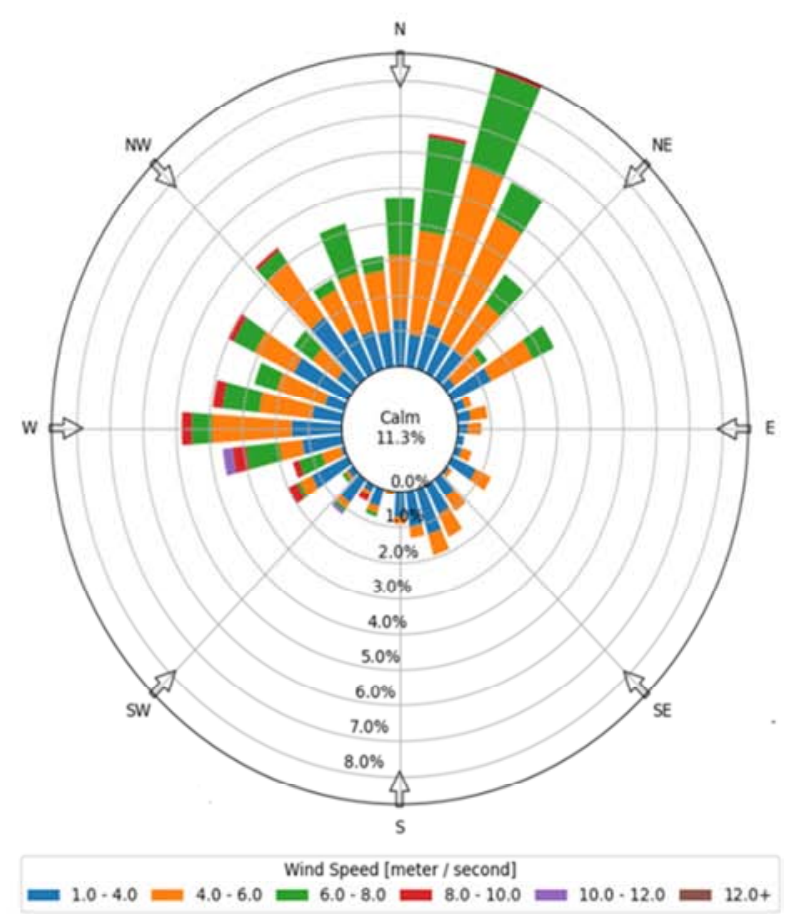

Autumn

Figure 3. Seasonal wind rose for 2020.

\subsubsection{Wind Speed}

Analysis of hourly wind speed data shows that the wind blows most frequently from the NW (North West direction) with the maximum wind speed reaching $6.09 \mathrm{~m} / \mathrm{s}$ and the average annual wind speed is $3 \mathrm{~m} / \mathrm{s}$ as shown in Figure 4 . 


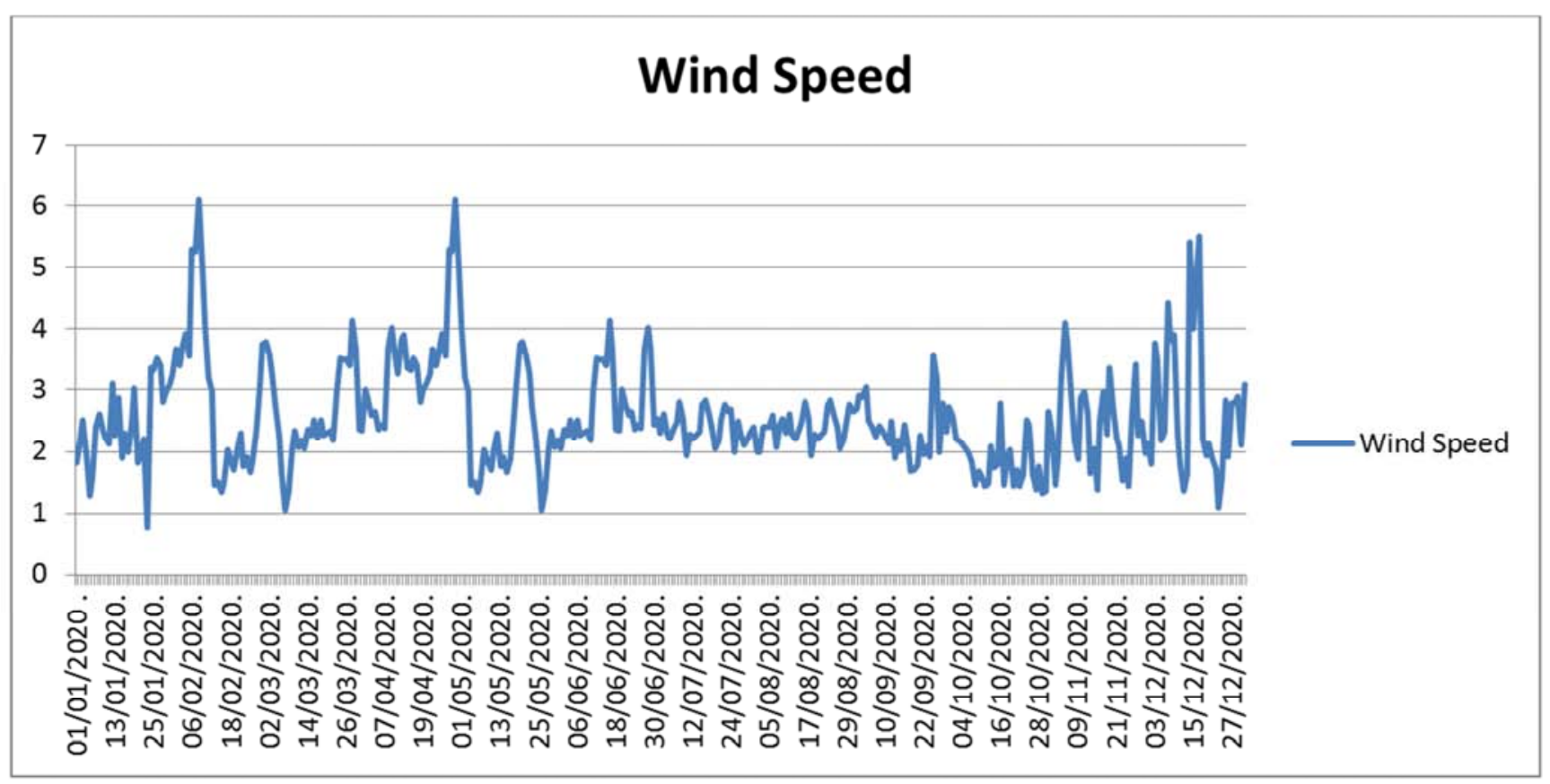

Figure 4. Wind speed distribution for the year2020.

\subsubsection{Temperature Analysis}

The temperature analysis changes from maximum in July with $43^{\circ} \mathrm{C}$ to minimum in January with $13^{\circ} \mathrm{C}$. The values of temperature in the study area are relatively high in summer months (June, July and august) as shown in Figure 5.

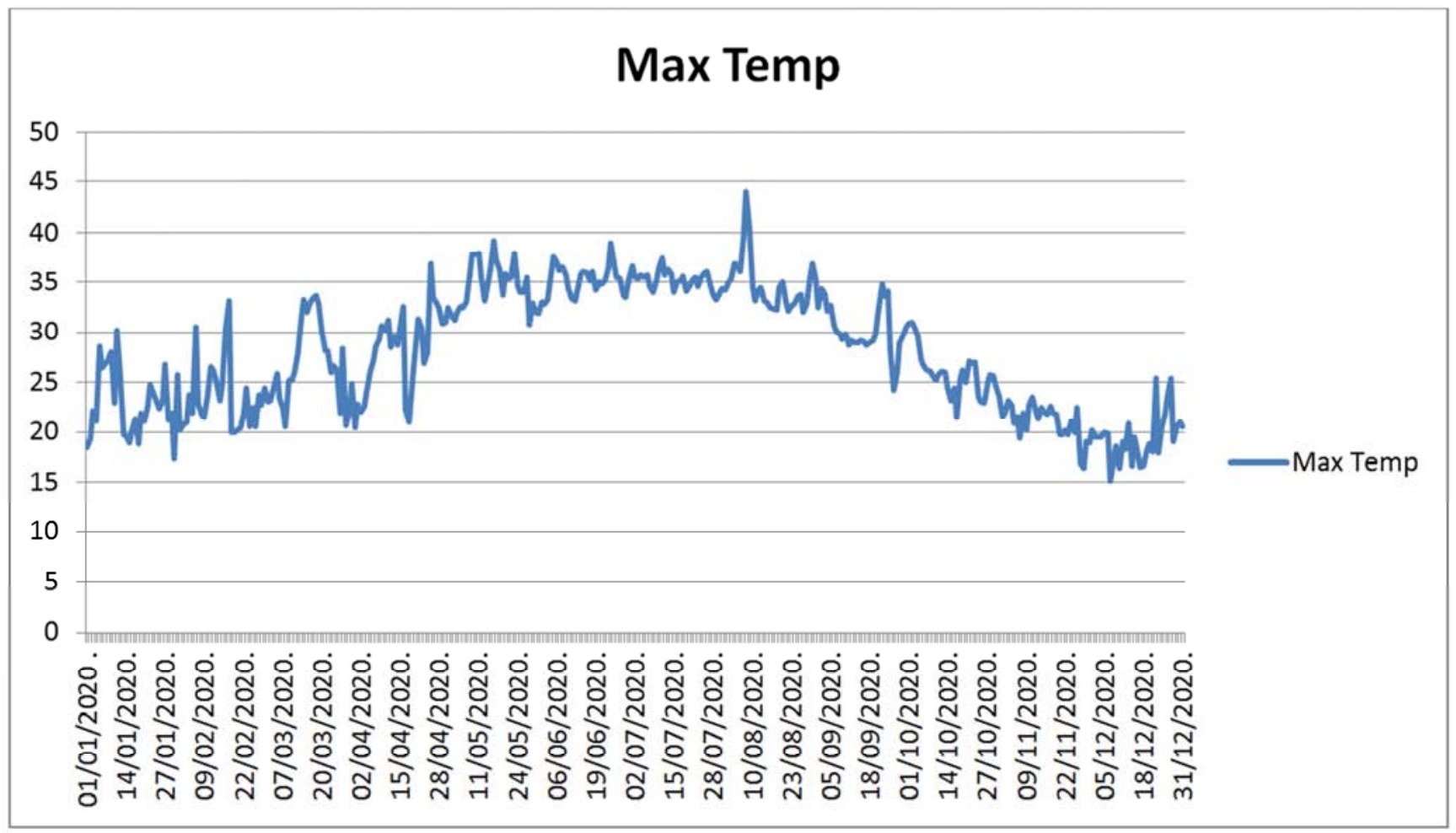

Figure 5. Temperature distributions for the year 2020.

\subsubsection{Relative Humidity Analysis}

The values of relative humidity in the study area are relatively high in summer months. The maximum and the minimum values of relative humidity are recorded in July and March as shown in Figure 6. 


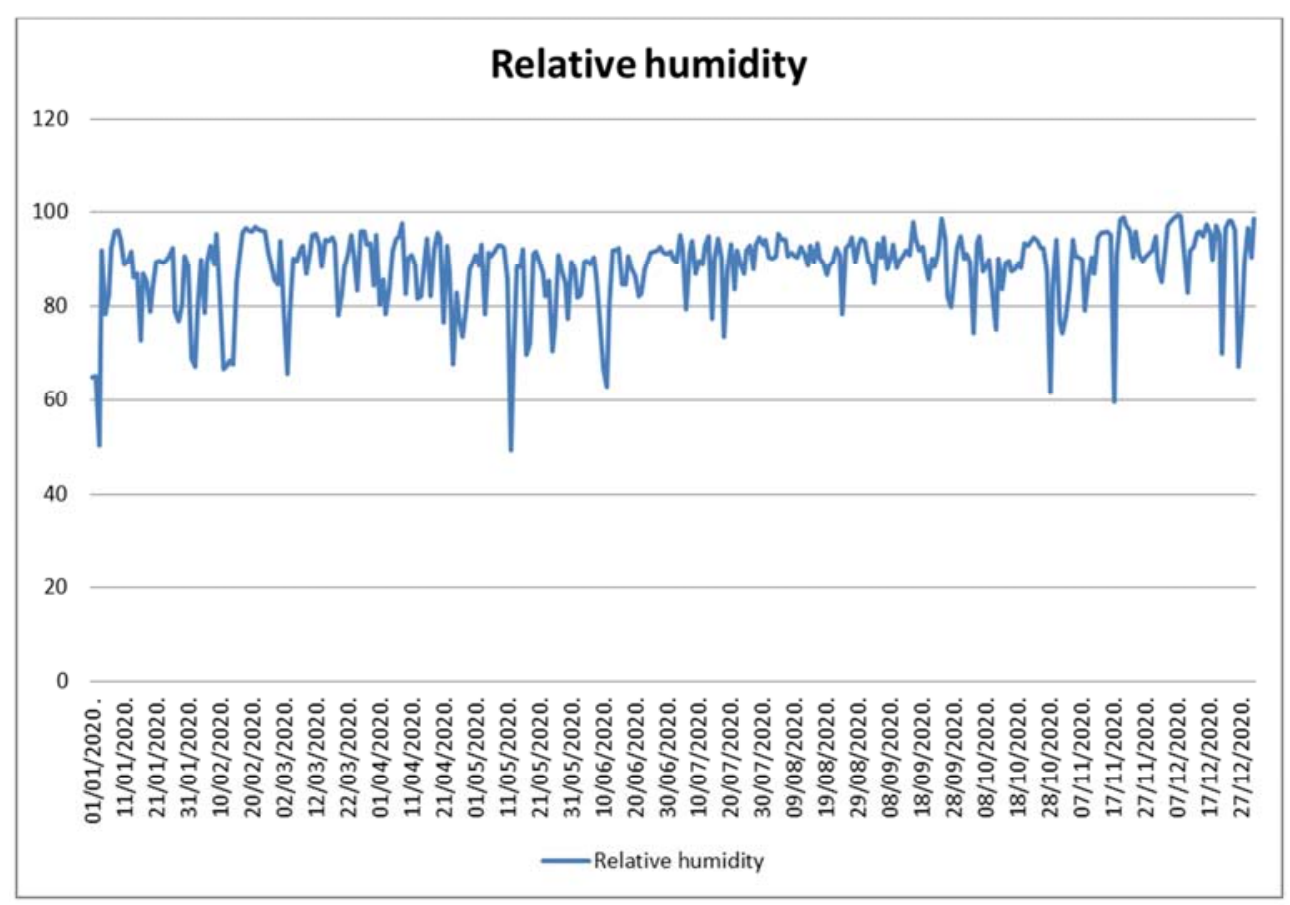

Figure 6. Relative humidity distribution for the year 2020.

\subsubsection{Atmospheric Stability Classes}

The hourly atmospheric stability classes are determined using wind speed and solar radiation levels or sky cover method [6]. The results indicate that the stability class D neutral condition was the more conservative than any other stability classes for all months except summer months (July and august) where the stability class B unstable condition is relatively higher than other one, this is due to high incoming solar radiation in summer season. The mixing height is defined the reflection of plume at upper boundary. This layer is highly affected by the type of atmospheric stability class. Where in case of unstable condition this layer has a high value can be reached to $3000 \mathrm{~m}$. This layer reduces under neutral and stable conditions.

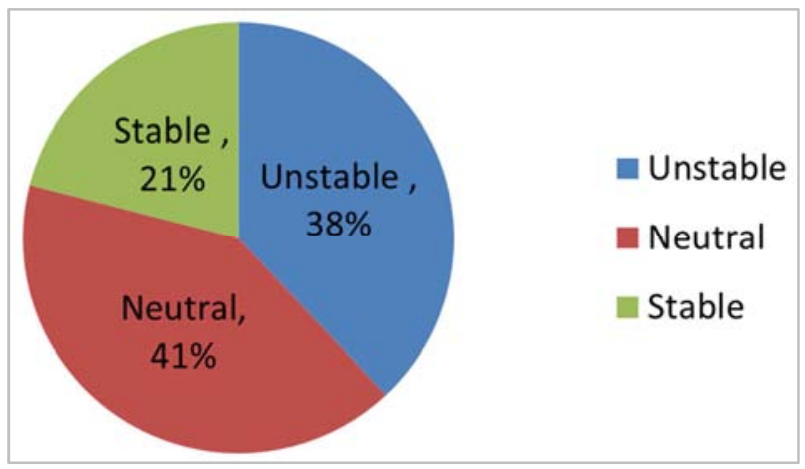

Figure 7. Atmospheric stability classes during 2020.

The Consideration Site is location inside the fence that determines the boundaries of the land, which belongs to the Egyptian Atomic Authority at Inshas area.

The Site is surrounding by the Ismailia Canal from the west. Such a canal branches the Nile River north of Cairo and runs up to the city of Esmailia. In the other direction, the site is surrounded by desert land, agricultural and industrial neighbourhoods.

\subsection{The HotSpot Code}

HotSpot [7] is a free license code that provides a fast method to evaluate the radiation effects associated with the atmospheric release of radioactive materials. It is based on a Gaussian model that estimates the short-range (less than 10 $\mathrm{km}$ ), and short-term (less than a few hours) predictions for downwind radiological impact following the release of radioactive material [8]. HotSpot uses the radiation dosimetry methodologies recommended by the International Commission on Radiological Protection (ICRP) [9, 10]. The estimations produced by HotSpot are conservative and the Gaussian model implemented. HotSpot is a product of Lawrence Livermore National Laboratory's National Atmospheric Release Advisory Center (NARAC) [11].

\subsection{Model Input}

The height of the release was $(50 \mathrm{~m})$. The wind was blowing from the southeast $\left(330^{\circ}\right)$. The delay time was 0 second. The height of a receptor was $(1.5 \mathrm{~m})$. The duration of the sample was ten minutes. Standard terrain is chosen because it yields the much more conservative results. This study was held on an assumption that the radionuclide source term of Cs-137 was $2.10 \mathrm{E}+15 \mathrm{~Bq}$.

A hypothetical severe accident scenario that results in the discharge of radioactive pollutants into the environment is chosen to show reactor safety [12]. The following scenarios use several types of stability classes and wind speeds to model an accident with a general fire. First scenario takes place for neutral condition wind speed is $3 \mathrm{~m} / \mathrm{s}$ and stability 
class is D. The second scenario is for stable condition Wind speed is $1 \mathrm{~m} / \mathrm{s}$ and stability class is F. It is clear that the output of the accident depends mainly on the type of stability classes and wind speed. The Third scenario is for unstable condition Wind speed is $6 \mathrm{~m} / \mathrm{s}$ and stability class is B.

\section{Results and Discussion}

\subsection{Senerio 1}

Figures 8 and 9 illustrate the evolution of the total effective dose (TED) as the plume travels with time to various distances from the point of release, with emission from the ground level. Within just few seconds of this event, a maximum TED of $1.2 \mathrm{E}+3 \mathrm{~Sv}$ is observed at $10 \mathrm{~m}$ from the release source. This value falls to be less than $1 \mathrm{mSv}$ at $7.6 \mathrm{Km}$. This demonstrates that only workers in close proximity to the reactor building will require special attention in order to reduce their doses [13]. Because they have been trained in dealing with radiation risks, action will be taken right away. The remaining staff working in no restricted zones will be radiation safe, as well as the population. The change in meteorological conditions on site was also per- formed to see the impact on the plume [14].

\subsection{Senerio 2}

Figures 10 and 11 illustrate the evolution of the total effective dose (TED) as the plume travels with time to various distances from the point of release, with emission from the ground level. Within just few seconds of this event, a maximum TED of $1.1 \mathrm{E}+4 \mathrm{~Sv}$ is observed at $10 \mathrm{~m}$ from the release source. This value falls to less than $15 \mathrm{~Sv}$ at $20 \mathrm{~m}$ then falls to $0.01 \mathrm{~Sv}$ at $1 \mathrm{Km}$. According to the doses assessment for stability class F, workers and the public who are close to the reactor building will need to pay close attention to reducing their doses by the time spent in that zone.

\subsection{Senerio 3}

Figures 12 and 13 illustrate the evolution of the total effective dose (TED) as the plume travels with time to various distances from the point of release, with emission from the ground level. Within just few seconds of this event, a maximum TED of $1.6 \mathrm{E}+2 \mathrm{~Sv}$ is observed at $10 \mathrm{~m}$ from the release source. This value falls to $0.1 \mathrm{mSv}$ at $20 \mathrm{Km}$.

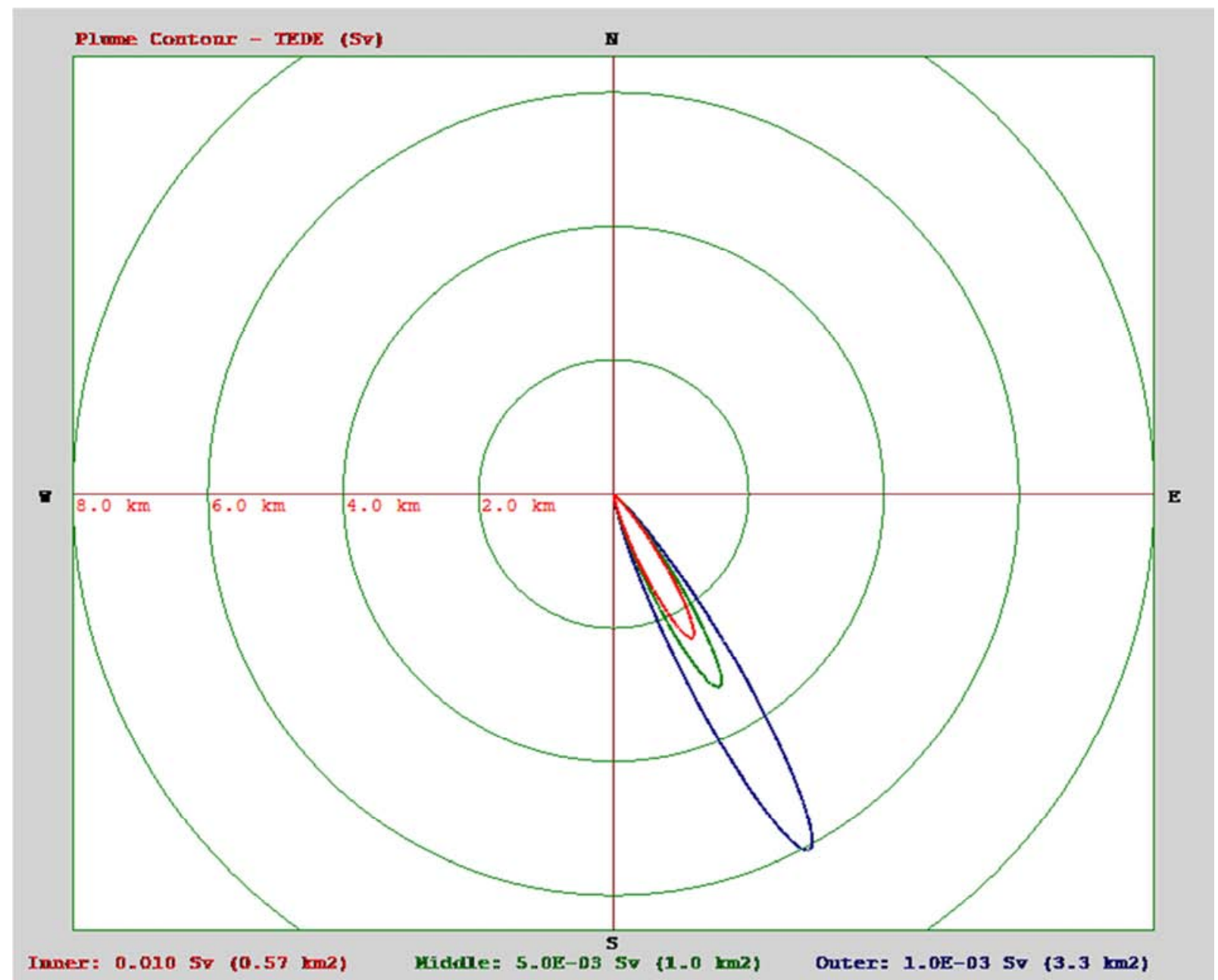

Figure 8. TEDE Contour Plot for the scenario 1 (dose contour values for the plume was 0.01 Sv (inner), 0.005Sv (middle) and 0.001 Sv (outer)). 


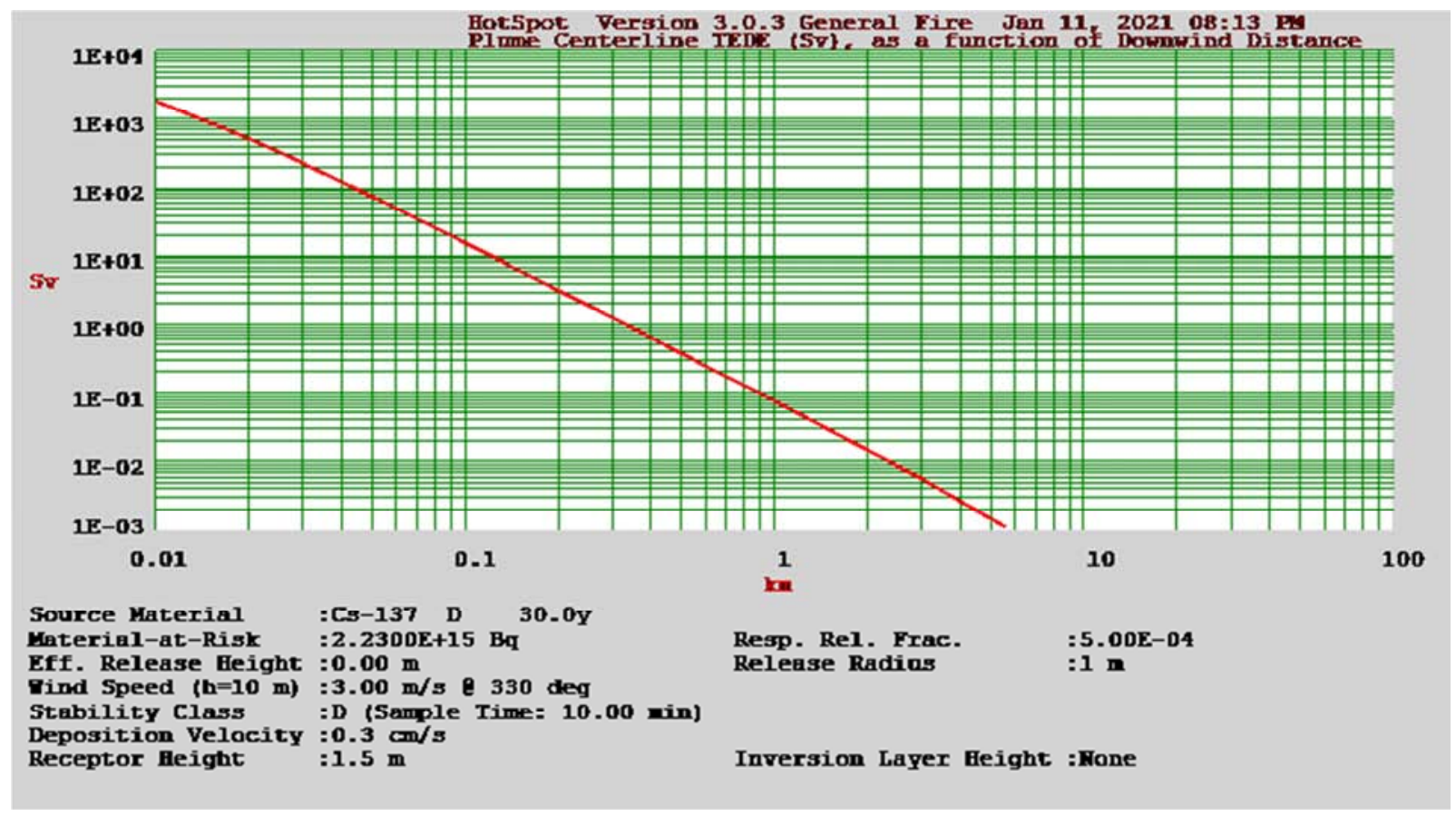

Figure 9. Total effective dose as a function of distance for scenario 1.

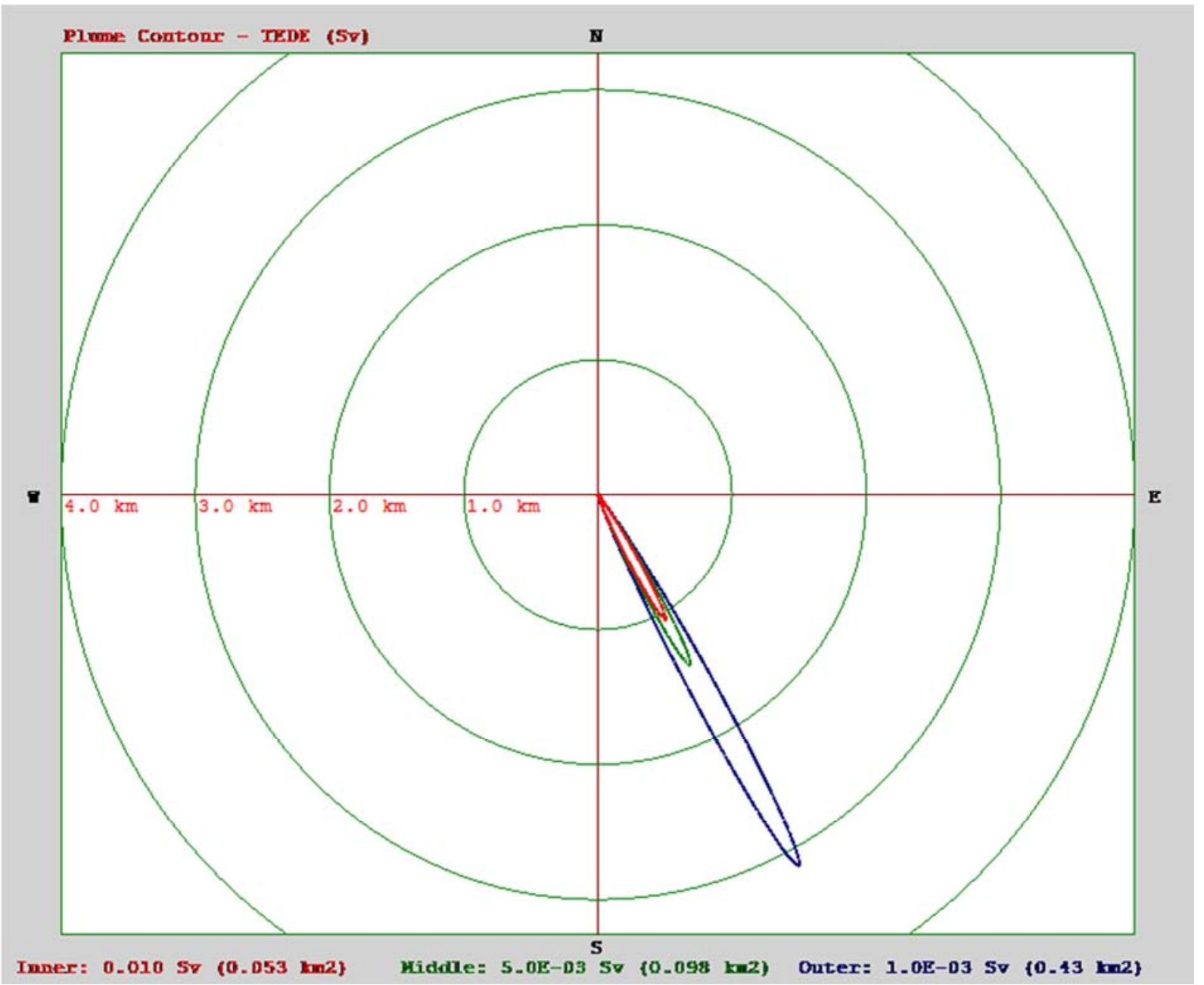

Figure 10. Total effective dose for the scenario 2 (dose contour values for the plume was 0.01Sv (inner), 0.005Sv (middle) and 0.001 Sv (outer)). 


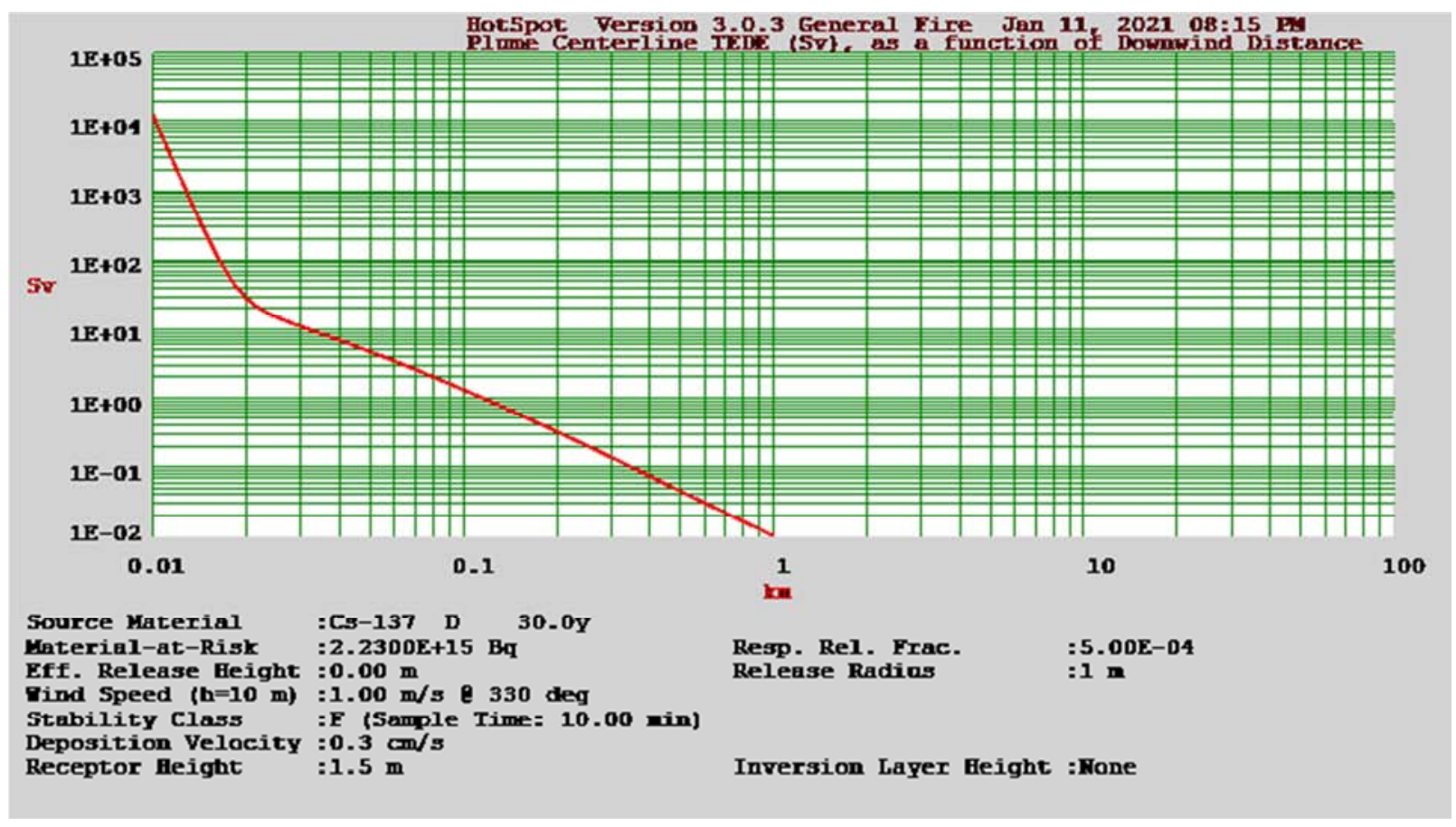

Figure 11. Total effective dose as a function of distance for scenario 2.

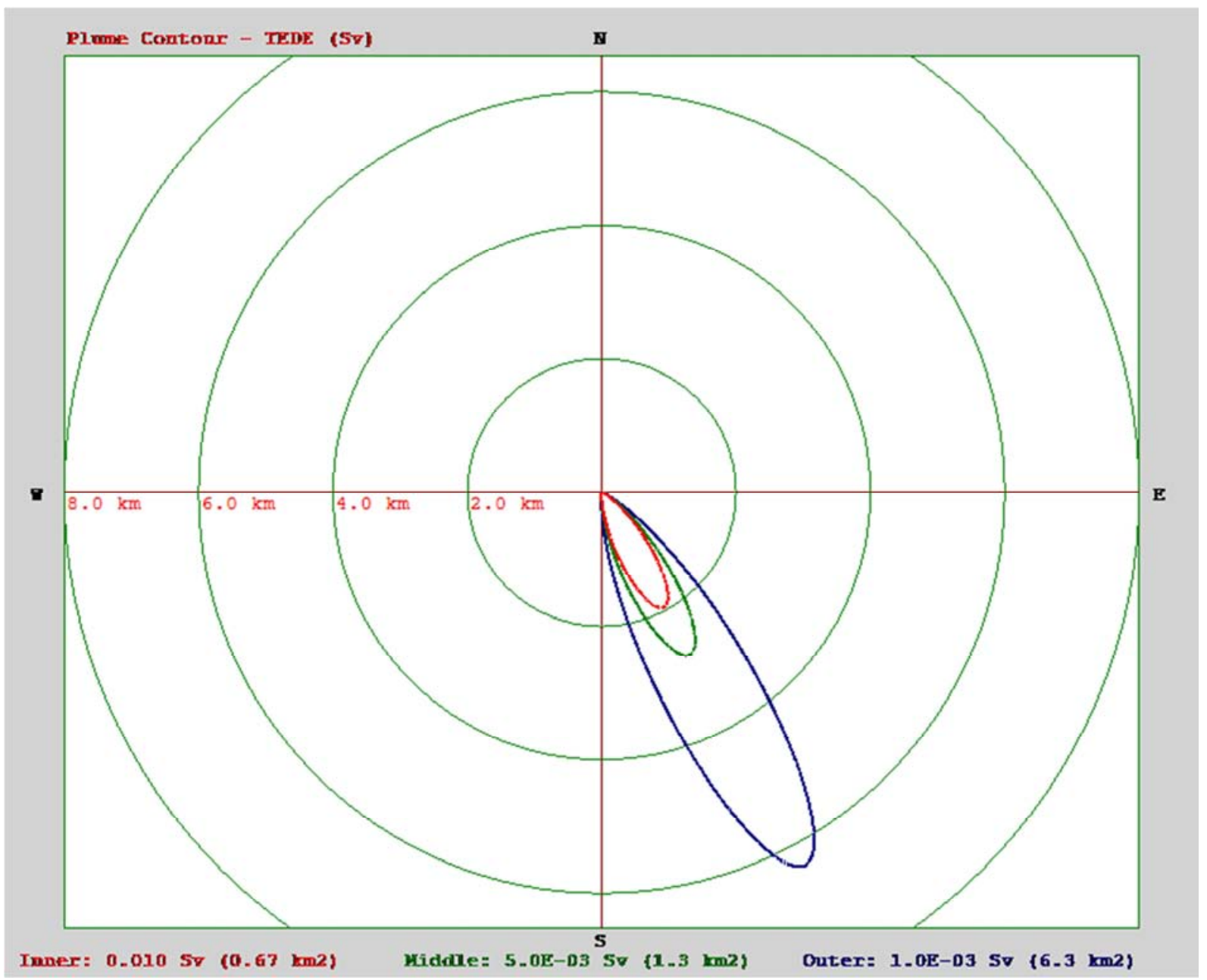

Figure 12. TEDE Contour Plot for the scenario 3 (dose contour values for the plume was 0.01 Sv (inner), 0.005Sv (middle) and 0.001mSv (outer)). 


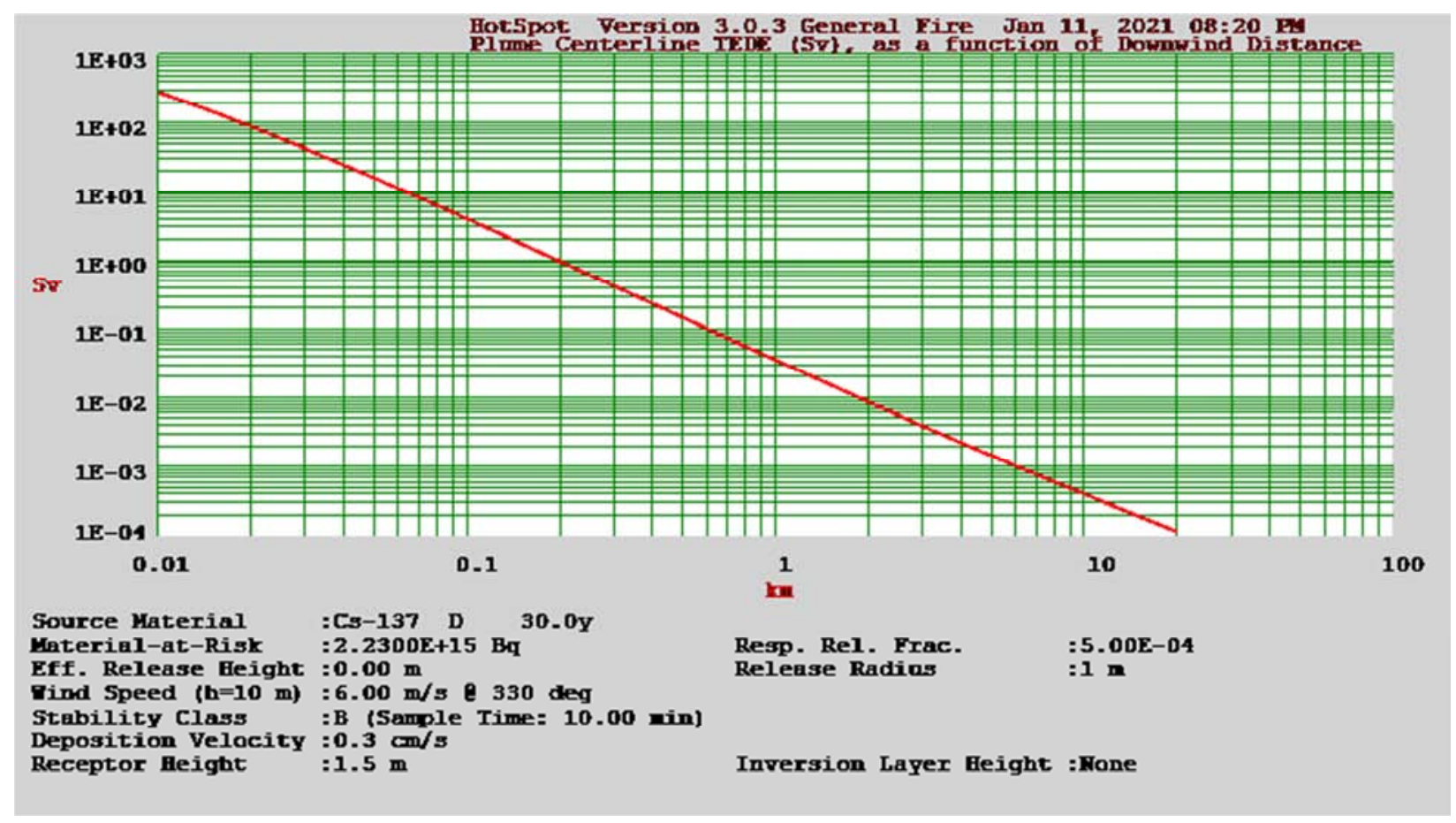

Figure 13. Total effective dose as a function of distance for scenario 3.

\section{Conclusion}

1) The hourly meteorological parameters of the Inshas site indicate that the hypothetical accident may occur under different meteorological conditions depending on the time of the accident. As a result, we carry more scenarios to cover all different meteorological conditions of different seasons of the year.

2) -stable condition for scenerio 2 gives the highest impact and the worest condition for the accident.

3) This paper, was studied the impact of different accident scenario causing a dispersion of radioactive substances into the atmosphere of research reactor.

4) The results of this study could be useful to emergency response personnel to quantify the dosimetric impact on people and the environment and provide adequate protective measures.

5) The emitted radionuclides may travel extended distance but will have no hazardous impact on the public.

\section{References}

[1] J. L. Muswema, G. B. Ekoko, V. M. Lukanda, J. K.-K. Lobo, E. O. Darko, E. K. Boafo. "Source term derivation and radiological safety analysis for the TRICO II research reactor in Kinshasa", Nuclear Engineering and Design, 2015.

[2] Z. Foudil, B. Mohamed, and Z. Taher, Estimating of Core Inventory, Source Term and Doses Results for NUR Research Reactor under a Hypothetical Sever Accident 'Progress in Nuclear Energy, Vol. 100, pp 365-372, 2017.

[3] Raza, s. s., Iqbal, M., 2005. Atmospheric Dispersion Modeling for an Accident Release from the Pakistan Research Reactor -
1 (PARR-1). Ann. Nucl. Energy 32, 1157.

[4] Zeggar Foudila, Belgaid Mohamedb, and Zidi Taha Estimating of core inventory, source term and doses results for the NUR research reactor under a hypothetical severe accident, Volume 100, September 2017, Pages 365-372.

[5] Safety Analysis Report of Egypt's Second Research Reactor (ETRR-2), (1995).

[6] IAEA, Derivation of the source term and analysis of the radiological consequences of research reactor accidents, safety reports series (2008). No. 53.

[7] HOTSPOT Code Version 2.06. Developed at the Lawrence Livermore National Laboratory, University of California, USA, 2014.

[8] Mariachiara Carestia1, Andrea Malizia1, Oscar Barlascini1, Eugenio Fiorini1, Paolo Maurizio Soave1, Gianna Latini, Orlando Cenciarelli1, Fabrizio D'Amico, Carlo Bellecci1, Pasquale Gaudio1 USE of the "HotSpot" Code for Safety and Security Analysis In Nuclear Power Plants: A Case Study. April 2016, Vol. 15.

[9] International Commission on Radiological Protection (ICRP), Basis for Doisimetric Quantities Used in Radiological Protection. ICRP, Ottawa, Canada, 2005.

[10] Steven, G. M, HotSpot, Health Physics Codes, Version 2.07.1, User's Guide. National Atmospheric Release Advisory Center, Lawrence Livermore National Laboratory, Livermore, CA 94550, 2010.

[11] Homann S. G. and Aluzzi F. HotSpot Health Physics Codes Version 3.0 User's Guide. National Atmospheric Release Advisory Center Lawrence Livermore. National Laboratory Livermore, CA 94550, 2013.

[12] Ned Xoubi. "Assessment of environmental radioactive surface contamination from a hypothetical nuclear research reactor accident", Heliyon, 2020. 
[13] Rentai, Y. Atmospheric dispersion of radioactive material in radiological risk assessment and emergency response. Progress in Nuclear Science and Technology, Vol. 1, 2011, pp. $7-13$.
[14] Van Dop, H., Atmospheric Distribution of Pollutants and Modelling of Air Pollution Dispersion, in Air Pollution. 1986, Springer Berlin Heidelberg: Berlin, Heidelberg. p. 107-147. 